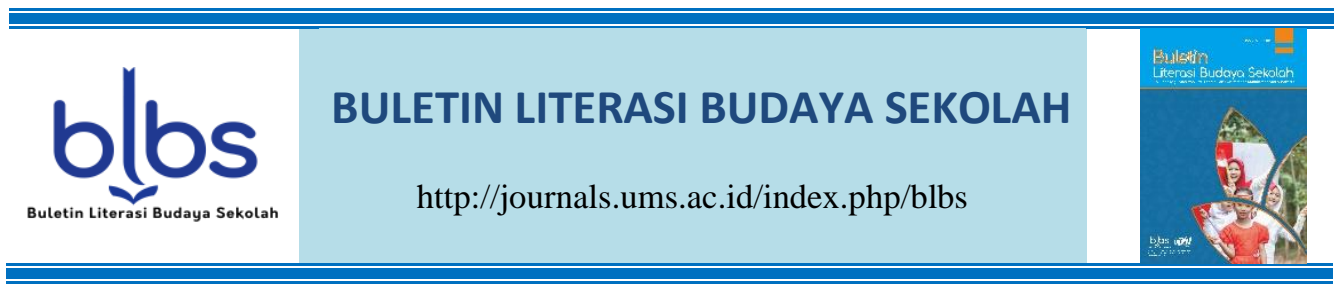

\title{
PEMBIASAAN SHOLAT DHUHA BERJAMA'AH TERHADAP PENDIDIKAN KARAKTER SISWA DI SMP MUHAMMADIYAH 4 SAMBI
}

\author{
Saryadi ${ }^{1}$, Septy Nur Amalia Putri ${ }^{2}$, Hastin Puspitasari ${ }^{3}$, \& Endang Setyaningsih ${ }^{4}$ \\ 1,2,3,4 Universitas Muhammadiyah Surakarta \\ Jl. Ahmad Yani Tromol Pos I, Surakarta, Indonesia
}

Email \& Phone: a420180053@student.ums.ac.id +62-271-717417

Submitted: 2020-08-19

DOI: $10.23917 /$ blbs.v2i2.12839

Accepted: 2020-09-09

Published: $2020-12-07$

\begin{tabular}{ll}
\hline Keywords: & \multicolumn{1}{c}{ Abstract } \\
\hline habituation & Strengthening character education (PPK) is one of the created \\
education & by the government which aims to create the next generation of \\
dhuha prayer & the nation who is academically intelligent and also physically \\
and mentally intelligent. Strengthening Character Education \\
that is commonly done is by doing habituation. One of the ways \\
of character education in the form of habituation that has been \\
implemented by SMP Muhammadiyah 4 Sambi is by \\
habituating the implementation of dhuha prayers in \\
congregation. This research was conducted to determine the \\
benefits of practicing dhuha prayer at SMP Muhammadiyah 4 \\
Sambi, which was carried out during the Introduction to \\
Preschool Environment 1 (PLP1) program between 2 weeks, in \\
February 2020 using descriptive methods with qualitative data. \\
The results of this study indicate that the habituation of dhuha \\
prayer in congregation as a strengthening of character \\
education carried out by students at SMP Muhammadiyah 4 \\
Sambi is positive towards student character such as the \\
character likes to establish friendship between students, the \\
character of mutual respect and respect, the character is \\
accustomed to remembering and getting closer. self to the \\
creator, the character of the loss of excessive individualism, \\
and the character of discipline to come on time to school, do \\
good activities repeatedly, and discipline to carry out religious \\
orders. From this it can be said that indeed the habituation of \\
dhuha prayer activities in congregation is beneficial to the \\
character of students.
\end{tabular}




\section{PENDAHULUAN}

Pendidikan karakter merupakan suatu cara mendidik murid-murid di sekolah agar memiliki kepribadian yang berguna bagi bangsa dan negara. Pendidikan karakter dapat dibina di sekolah maupun di rumah. Keduanya berperan penting dalam pembentukan karakter suatu individu, seperti yang dipaparkan Listiawati (2019) tentang implementasi penguatan pendidikan karakter di sekolah dan yang disampaikan oleh Josua et al. (2019) mengenai nilai-nilai dalam keluarga yang berpengaruh terhadap habituasi karakter remaja dengan ibu yang bekerja. Saat ini, tidak jarang para pengamat pendidikan mulai menegaskan tentang pentingnya pendidikan karakter. Murid dididik tidak hanya secara akademis namun juga secara kepribadiannya. Seperti apa yang telah disebutkan dalam Peraturan Presiden Nomor 87 tahun 2017 mengenai Penguatan Pendidikan Karakter Bab I pasal ayat (1) yaitu "Penguatan Pendidikan Karakter yang selanjutnya disingkat PPK adalah gerakan pendidikan di bawah tanggung jawab satuan pendidikan untuk memperkuat karakter peserta didik melalui harmonisasi oleh hati, oleh rasa, oleh pikir, dan olah raga dengan pelibatan dan kerja sama antara satuan pendidikan, keluarga, dan masyarakat sebagai bagian dari Gerakan Nasional Revolusi Mental (GNRM)." Dan pada intinya semua pendidikan karakter yang sedang digalakkan punya tujuan yang sama, yaitu untuk memenuhi nilai hikmah pendidikan karakter yang meliputi religius, jujur, toleransi, disiplin, kerja keras, kreatif, mandiri, demokratis, rasa ingin tahu, semangat kebangsaan, cinta tanah air, menghargai prestasi, bersahabat/komunikatif, cinta damai, gemar membaca, peduli lingkungan, peduli sosial, dan tanggung jawab (Santoso et al., 2019).

Fenomena merosotnya karakter berbangsa di tanah air dapat disebabkan lemahnya pendidikan karakter dalam meneruskan nilai-nilai kebangsaan pada saat alih generasi. Di samping itu, lemahnya implementasi nilai-nilai berkarakter di lembaga-lembaga pemerintahan dan kemasyarakatan ditambah berbaurnya arus globalisasi telah mengaburkan kaidah-kaidah moral budaya bangsa yang sesungguhnya bernilai tinggi. Akibatnya, prilaku-prilaku tidak normatif semakin jauh merasuk ke dalam dan berakibat merusak kehidupan berbangsa (Supiana \& Sugiharto, 2017). Itulah mengapa pendidikan karakter saat ini adalah hal yang penting, karena pendidikan karakter adalah cara agar menciptakan calon penerus bangsa yang baik, baik dari akademis, lahir dan batin. Hal ini membuat setiap sekolah berusaha mendidik murid-murid dari segi karakter untuk mewujudkan suatu gerakan nasional revolusi mental, seperti apa yang dapat diharapkan bagi bangsa dan negara (Marzuki, 2013; Safi'i et al., 2019).

Dari sekian banyak metode pendidikan karakter yang diterapkan disekolah, salah satunya adalah pembiasaan untuk melakukan sholat dhuha berjama'ah. Kegiatan ini merupakan salah satu kegiatan yang mendidik karakter agar memiliki kecerdasan secara spiritual (Wahyono, 2017). Pembiasaan seperti ini memang bukan hanya dilakukan di SMP Muhammadiyah 4 Sambi. Namun, memang diketahui bahwa pembiasaan ini membawa dampak bagi kepribadian murid, terutama murid di SMP Muhammadiyah 4 Sambi.

Sholat dhuha merupakan salah satu ibadah dalam agama islam yang biasa dilakukan pada saat waktu dhuha (setelah matahari terbit hingga sebelum masuk waktu solat dzhuhur) hukum mengerjakan solat ini adalah sunnah (ibadah yang tidak wajib namun sangat dianjurkan untuk dikerjakan). Beberapa sekolah kini telah 
Saryadi ${ }^{1}$, Septy Nur Amalia Putri ${ }^{2}$, Hastin Puspitasari ${ }^{3}$, \& Endang Setyaningsih ${ }^{4}$, Pembiasaan Sholat Dhuha Berjama'ah

menjadikan kegiatan sholat dhuha berjama'ah menjadi kegiatan yang bertujuan dalam pendidikan karakter murid, dalam penelitian Rajab, (2019) dampak pembiasaan shalat dhuha dan shalat zuhur berjamaah cuku baik terhadap pembinaan akhlak siswa, baik akhlak kepada Allah Swt begitu juga akhlak sesama manusia. Misalnya saja siswa mampu menerapkan beberapa sikap atau akhlak terpuji terhadap sesama manusia, yaitu rasa persaudaraan yang diaplikasikan melalui silaturrahmi, sopan santun terhadap setiap orang, tolong menolong bersikap jujur, baik perkataan maupun perbuatan, begitu pula kedisiplinannya meningkat dari tahun ke tahun. Pernyataan di atas sejalan dengan temuan dari hasil penelitian Muhamadi \& Hasanah, (2019) yang menemukan bahwa melalui aktivitas atau kegiatan yang di dalamnya ada interkasi seperti kegiatan ekstrakurikuler, ternyata kegiatan seperti ini dapat menumbuhkan karakter peduli terhadap sesama teman.

Oleh sebab itu, penting kiranya untuk melihat manfaat pembiasaan sholat dhuha berjama'ahdi SMP Muhammadiyah 4 Sambiterhadap pendidikan karakter pada siswa didiknya.

\section{METODE}

Metode yang digunakan merupakan metode penelitian deskriptif dengan menggunakan data kualitatif yang di dapat dari hasil obeservasi terhadap 158 murid SMP Muhammadiyah 4 Sambi selama 2 minggu, untuk mengamati bagaimana sistem pendidikan karakter yang dilakukan oleh guru-guru yang ada di SMP Muhammadiyah 4 Sambi.

Proses obeservasi adalah dengan cara mengamati keseluruhan kegiatan sholat dhuha berjama'ah yang dilaksanakan di SMP Muhammadiyah 4 Sambi setiap pagi, setiap hari selasa sampai dengan hari sabtu selama kegiatan Pengenalan Lingkungan Persekolahan 1 (PLP1) berlangsung selama 2 minggu, pada bulan Februari tahun 2020.

\section{HASIL DAN PEMBAHASAN}

SMP Muhammadiyah 4 Sambi, adalah sekolah menengah pertama yang berada dalam yayasan pendidikan muhammadiyah yang berlokasi di kecamatan Sambi kabupaten Boyolali. Sekolah ini memiliki jumlah total murid sebanyak 158 orang. Menggunakan kurikulum KTSP untuk kelas IX dan kurikulum 2013 untuk kelas VII dan VIII, SMP Muhammadiyah 4 Sambi juga memiliki program pembelajaran yang terdiri dari tiga jenis, yaitu program ekstrakulikuler, program kokulikuler, dan program intrakulikuler. Program ekstrakulikuler yang ada di SMP Muhammadiyah 4 Sambi diantaranya adalah Baca Tulis Al-Qur'an (BTA); Hizbul Wathan (HW); dan Tapak Suci (TS), lalu program kokulikuler yang ada di SMP Muhammadiyah 4 Sambi adalah les atau jam tambahan bagi kelas IX guna sebagai bentuk dari persiapan diri untuk menghadapi Ujian Nasional (UN), dan yang terakhir adalah program intrakulikuler yang berupa kegiatan belajar mengajar inti yang wajib dilaksanakan, yaitu kegiatan belajar mengajar (KBM); upacara setiap senin pagi; dan pembiasaan solat dhuha berjama'ah.

Pembiasaan sholat dhuha berjama'ah merupakan salah satu dari intrakulikuler yang ada di SMP Muhammadiyah 4 Sambi yang berperan sebagai penerapan penguatan pendidikan karakter, terutama dalam mendidik murid-murid 
SMP Muhammadiyah 4 Sambi menjadi murid-murid yang memiliki karakter yang islami, mengingat pula bahwa sekolah ini berada dalam naungan dari Muhammadiyah. Diharapkan dengan melaksanakan pembiasaan sholat dhuha berjam'ah seperti dapat membuat murid-murid di SMP Muhammadiyah 4 Sambi menjadi murid yang memiliki akhlak yang baik, baik dari segi norma maupun segi agama. Pembentukan karakter akhlak yang baik juga pernah dilakukan dalam penelitiannya Hayati, (2017) dan Wulandari, (2019) yang menemukan bahwa dengan melakukan pembiasaan dholat dhuha dapat membentuk karakter akhlakul karimah seperti disiplin, tanggung jawab, fokus/berpikiran jernih, dan mandiri.

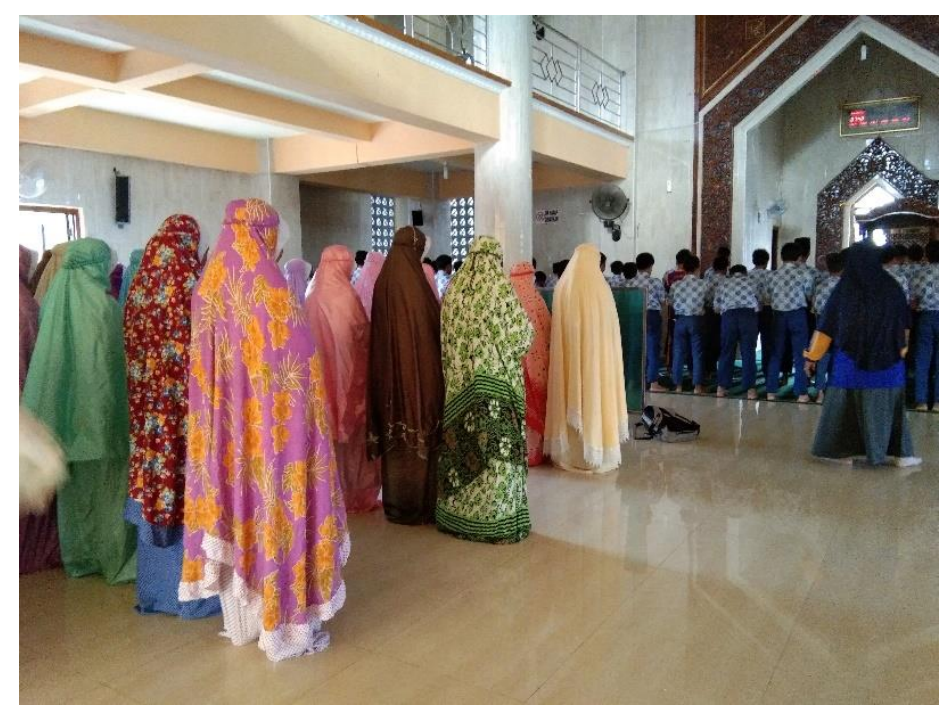

Gambar 1 murid SMP Muhammadiyah 4 Sambi sedang melaksanakan solat dhuha berjama'ah

Pembiasaan sholat dhuha berjama'ah dilaksanakan setiap hari kecuali pada hari senin, dikarenakan pada saat hari senin jam pelajaran pertama telah diisi oleh upacara pengibaran bendera. Waktu pelaksanaan kegiatan ini pada saat jam pelajaran pertama adalah atau sekitar pukul 07.15 sampai 08.00 WIB. Pelaksanaannya terdiri dari beberapa tahapan. Pertama, saat jam pelajaran pertama dimulai murid-murid akan dikumpulkan di masjid. Lalu setelah seluruh murid telah berkumpul, sholat dhuha berjama'ah akan dimulai, biasanya salah satu guru di SMP Muhammadiyah 4 Sambi akan menjadi imamnya. Lalu ketika sholat selesai murid-murid akan diminta untuk berdzikir dan berdo'a sendiri-sendiri terlebih dahulu. Kemudian, kegiatan dilanjutkan dengan berdo'a bersama yang dipinpin oleh beberapa murid lain yang duduk di depan menghadap temantemannya. Setelah selesai berdo'a bersama kepala sekolah atau guru-guru yang mewakili akan memberikan amanat atau wejangan kepada murid-murid sekitar 5 sampai 10 menit. Lalu kegiatan terakhir yang menutup kegiatan sholat dhuha berjama'ah ini adalah tadarus bersama. Murid-murid akan dibagikan juz 'amma terlebih dahulu, lalu mereka akan membacanya bersama-sama. Biasanya muridmurid akan membaca surah al-fatihah, surah an-nas, surah al-falaq, surah al-ikhlas, dan surat an-naba'. Selain itu, setelah rangkaian sholat dhuha berjama'ah ini 
Saryadi ${ }^{1}$, Septy Nur Amalia Putri ${ }^{2}$, Hastin Puspitasari ${ }^{3}$, \& Endang Setyaningsih ${ }^{4}$, Pembiasaan Sholat Dhuha Berjama'ah

selesai, murid-murid akan diadakan pengumpulan infaq yang biasa dilakukan setiap selasa dan kamis.

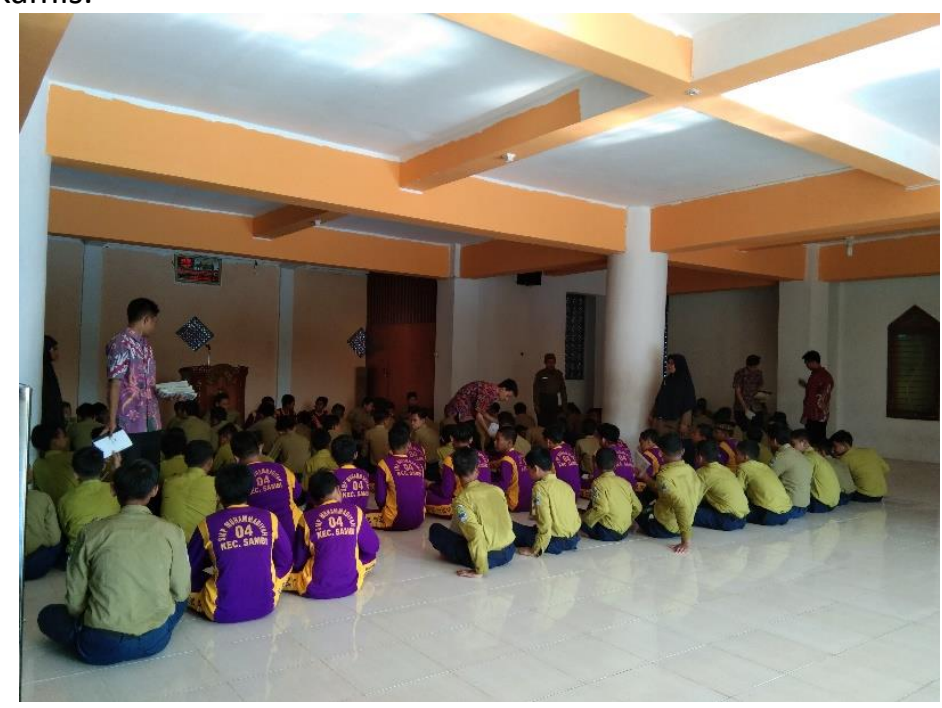

Gambar 2 pembagian juz 'amma kepada murid SMP Muhammadiyah 4 Sambi sebelum kegiatan tadarus dimulai

Setiap rangkaian kegiatan dalam pembiasaan sholat dhuha ini memiliki manfaatnya masing-masing. Seperti sholat dhuha berjama'ah yang mendidik murid SMP Muhammadiyah 4 Sambi adalah saling menjalin silahturahmi antar murid, saling menghargai dan menghormati, terbiasa untuk selalu mengingat dan memohon kepada Allah SWT. Siswa yang saling berinteraksi akan mengurangi sisi individualisme yang berlebihan, sehingga murid lebih mudah bergaul dengan murid lainnya. Kegiatan tadarus yang mebuat murid di SMP Muhammadiyah $4 \mathrm{Sambi}$ menjadi terbiasa untuk membaca, mendengarkan, atau bahkan menghapal beberapa surah di dalam Al-Qur'an. Lalu kegiatan infaq yang diadakan setiap selasa dan kamis akan memberikan dampak kepada murid yaitu agar tidak pelit, dan belajar ikhlas untuk memberikan sebagian rezekinya kepada orang lain yang lebih membutuhkan. Selain itu, sholat dhuha berjama'ah juga mendidik siswa untuk disiplin, untuk datang sekolah tepat waktu, untuk melakukan kegiatan baik secara berulang, dan untuk disiplin menjalankan perintah agama. Hal ini sesuai dengan hasil penelitian Khoirida, (2017) yang menyatakan bahwa intensitas melaksanakan sholat dhuha berpengaruh signifikan terhadap motivasi belajar siswa dan penelitian Indriani \& Prasetyo, (2019) yang menemukan bahwa pembinaan karakter disiplin berkendara pada pendidikan kewarganegaraan sangat diperlukan karena berdampak positif terhadap siswa didik SMP Negeri 9 Yogyakarta.

\section{SIMPULAN}

Pembiasaan sholat dhuha yang dilaksanakan di SMP Muhammadiyah 4 Sambi memberikan dampak yang baik bagi murid SMP Muhammadiyah 4 Sambi, terutama dari segi pendidikan karakter. Terlihat bahwa manfaat yang dihasilkan dari kegiatan murid selalu mengingat Allah SWT, menjadi suka bergaul dengan murid lainnya, disiplin waktu, ikhlas, dan terbiasa untuk melakukan hal-hal baik. 
Hayati, S. N. (2017). Manfaat Sholat Dhuha Dalam Pembentukan Akhlakul Karimah Siswa (Studi Kasus Pada Siswa Kelas Xi Man Purwoasri Kediri Tahun Pelajaran 2014 2015). Spiritualita, 1(1), 43-54.

Indriani, W., \& Prasetyo, D. (2019). Pembinaan Karakter Disiplin Berkendara Melalui Pembelajaran Pendidikan Kewarganegaraan Dan Budaya Disiplin. Jurnal Pendidikan Karakter, 1, 43-52.

Josua, D. P., Sunarti, E., \& Krisnatuti, D. (2019). Nilai-Nilai Dalam Keluarga Yang Berpengaruh Terhadap Habituasi Karakter Remaja Dengan Ibu Bekerja. Jurnal Pendidikan Karakter, 1, 80-92.

Khoirida, J. (2017). Pengaruh Intensitas Sholat Dhuha Terhadap Efikasi Diri Siswa Dalam Menghadapi Ujian Nasional: Studi Kasus Mi Miftahul Huda Tamansari Kecamatan Mranggen Kabupaten Demak.

Listiawati, N. (2019). Implementasi Penguatan Pendidikan Karakter Di Sdn 9 Kota Mataram Nusa Tenggara Barat. Jurnal Pendidikan Karakter, 1, 31-42.

Marzuki. (2013). Revitalisasi Pendidikan Agama Di Sekolah Dalam Pembangunan Karakter Bangsa Di Masa Depan. Jurnal Pendidikan Karakter, 1, 64-76.

Muhamadi, S. I., \& Hasanah, A. (2019). Penguatan Pendidikan Karakter Peduli Sesama Melalui Kegiatan Ekstrakurikuler Relawan. Jurnal Pendidikan Agama Islam, 16(1), 95-114. Https://Doi.Org/10.14421/Jpai.2019.161-06

Rajab. (2019). Implementasi Program Shalat Dhuha Dan Shalat Zuhur Berjamaah Dalam Pembentukan Akhlak Siswa (Studi Pada Sekolah Sd Al Hira Permata Nadiah Medan). Ansiru Pai : Pengembangan Profesi Guru Pendidikan Agama Islam, 3(2), 73-78. Https://Doi.Org/10.30821/Ansiru.V3i2.5851

Safi'i, I., Warni, S., \& Yanti, P. G. (2019). Persepsi Guru Bahasa Indonesia Tentang Hubungan Antara Penerapan Full Day School Dengan Penguatan Karakter Siswa. Jurnal Pendidikan Karakter, 9(2), 259-268.

Santoso, J., Wahyudi, A. B., Sabardila, A., Setiawaty, R., \& Kusmanto, H. (2019). Nilai Pendidikan Karakter Pada Ungkapan Hikmah Di Sekolah Dasar Se-Karesidenan Surakarta. Jurnal Pendidikan Karakter, 1, 63-79.

Supiana, \& Sugiharto, R. (2017). Pembentukan Nilai-Nilai Karakter Islami Siswa Melalui Metode Pembiasaan (Studi Kasus Di Madrasah Tsanawiyah Terpadu Ar-Roudloh Cileunyi Bandung Jawa Barat). Jurnal Educan, 01(01), 89-109.

Wahyono, N. (2017). Hubungan Shalat Dhuha Dengan Kecerdasan Emosional Siswa Kelas X Di Sma Muhammadiyah 7 Surabaya. Tadarus: Jurnal Pendidikan Islam, 6(2).

Wulandari, D. (2019). Dampak Pembiasaan Solat Dhuha Berjamaah Terhadap Peningkatan Moral Siswa Di Sma Syarif Hidayatullah Grati. 